\title{
Kinetics and Mechanism of Electron Transfer to Heptavalent Manganese by DL-Aspartic Acid in Alkaline Aqueous and Micellar Media
}

\author{
M. Sanjana, ${ }^{1}$ A. K. Patnaik, ${ }^{2}$ S. K. Badamali, ${ }^{1}$ and P. Mohanty ${ }^{1}$ \\ ${ }^{1}$ Department of Chemistry, Utkal University, Bhubaneswar 751004, India \\ ${ }^{2}$ Department of Chemistry, Khallikote Autonomous College, Berhampur 760001, India
}

Correspondence should be addressed to M. Sanjana; msanjanaa@gmail.com

Received 30 June 2012; Accepted 15 September 2012

Academic Editor: Ioannis G. Roussis

Copyright (C) 2013 M. Sanjana et al. This is an open access article distributed under the Creative Commons Attribution License, which permits unrestricted use, distribution, and reproduction in any medium, provided the original work is properly cited.

\begin{abstract}
The kinetics and mechanism of the electron transfer of $D L$-Aspartic acid (Asp) by Mn (VII) in alkaline medium has been studied spectrophotometrically over the range $2.0 \leq 10^{3}[$ Asp $] \leq 5.0 \mathrm{~mol} \mathrm{dm}^{-3} ; 0.01 \leq\left[\mathrm{OH}^{-}\right] \leq 0.05 \mathrm{~mol} \mathrm{dm}^{-3} ; 298 \leq T \leq 318 \mathrm{~K}$ and $I=0.05 \mathrm{~mol} \mathrm{dm}{ }^{-3}\left(\mathrm{KNO}_{3}\right)$. The reaction exhibits first-order dependence in $\left[\mathrm{MnO}_{4}{ }^{-}\right]_{T}$ but shows fractional-order dependence in both $[\mathrm{Asp}]_{T}$ and $\left[\mathrm{OH}^{-}\right]_{T}$. The reaction was studied in the presence of sodium dodecyl sulfate (SDS); an increase in the rate with the increase in the micellar concentration was observed. The products were characterized by spectral analysis. A mechanism involving free radicals is proposed. Asp binds $\mathrm{MnO}_{4}{ }^{-}$to form a complex that subsequently decomposes to products. Activation parameters $\Delta H^{\circ}\left(\mathrm{kJ} \mathrm{mol}^{-1}\right)$ and $\Delta S^{\circ}\left(\mathrm{JK}^{-1} \mathrm{~mol}^{-1}\right)$ for the reaction are $5.62 \pm 0.35$ and $-227.65 \pm 1.1$, respectively. The negative value of $\Delta S^{\circ}$ indicates that oxidation occurs via inner sphere mechanism.
\end{abstract}

\section{Introduction}

Study of oxidation of amino acids has received considerable attention due to the importance of degradation of these compounds in biological systems. The Aspartic acid is a nonessential amino acid which is found abundantly in plant proteins especially in sprouting seeds. This can be manufactured in the body from oxaloacetic acid. It is of paramount importance in the metabolism during construction of amino acids and biochemicals in the citric acid cycle [1]. Among the biochemicals that are synthesized from aspartic acid are asparagine, arginine, lysine, methionine, threonine, isoleucine, and several nucleotides.

Although the kinetics of oxidation of aspartic acid has been studied using different oxidants [2-9], the current work is an attempt to understand the redox chemistry of permanganate oxidation in alkaline media as well as in micellar media and to derive a plausible mechanism.

\section{Experimental}

All chemicals used were of reagent grade. Double distilled water was used throughout the work. Stock solution of $D L$ Aspartic acid (SRL Chemicals) was prepared by dissolving the appropriate amount of the sample in double distilled water. The stock solution of $\mathrm{KMnO}_{4}$ (Merck) was prepared by using double distilled water and was stored in a dark place. It was standardized against oxalic acid by following the literature method [10]. $\mathrm{NaOH}$ and $\mathrm{KNO}_{3}$ were used to maintain the required alkalinity and ionic strength, respectively. The solution of sodium dodecyl sulfate was prepared by dissolving calculated amount of SDS (Merck) in double distilled water.

During kinetic investigation, the $\mathrm{pH}$ was maintained using a SYSTRONICS $\mu \mathrm{pH}$ system-361 equipped with a combination of glass $\mathrm{Ag} / \mathrm{AgCl} / \mathrm{Cl}^{-}(3 \mathrm{M} \mathrm{NaCl})$ electrode. It was calibrated with standard buffers of $\mathrm{pH} 4.0,7.0$, and 9.0 
(Merck). Absorbance was recorded with a Cecil CE-7200 UVvisible spectrophotometer equipped with a CE-2024 thermoelectric controller. Ten-millimeter quartz Suprasil cuvettes were used. IR spectra were taken in Varian FTIR spectrophotometer (USA).

\section{Kinetic Measurements}

The oxidation of $D L$-Aspartic acid by $\mathrm{KMnO}_{4}$ was followed under pseudo-first-order conditions where $D L$-Aspartic acid was taken excess over $\mathrm{MnO}_{4}{ }^{-}$at $25^{\circ} \mathrm{C} \pm 0.1^{\circ} \mathrm{C}$. The reaction was initiated by mixing the required quantities of previously thermostated solutions of $\mathrm{MnO}_{4}{ }^{-}$and $\mathrm{DL}$-Aspartic acid, which also contained definite quantities of $\mathrm{NaOH}$ and $\mathrm{KNO}_{3}$ to maintain required ionic strength. The progress of the reaction was followed by measuring the decrease in absorbance at $525 \mathrm{~nm}$ with time using a conventional mixing technique. $A_{\infty}$ was measured after the completion of the reaction (approximately after 24 hours of mixing) when the absorbance became almost constant. The plot of $\ln \left(A_{t}-A_{\infty}\right)$ versus $t$ was found to be linear as indicated in the following equation:

$$
\ln \left(A_{t}-A_{\infty}\right)=\ln \left(A_{0}-A_{\infty}\right)-k_{\text {obs }} t,
$$

where $A_{t}$ and $A_{\infty}$ are absorbance of the reaction mixture at time, $t$, and at equilibrium, respectively. The correlation coefficients $\left(R^{2}\right)$ of the plots used to determine $k_{\text {obs }}$ were found to be 0.99 . The pseudo-first-order rate constant $\left(k_{\text {obs }}\right)$ was calculated by the least squares method from the above relationship. The redox reactions were followed for about 3 half lives. The reported rate data represented as an average duplicate runs were reproducible to within $\pm 3 \%$.

\section{Results}

The electron transfer reaction between DL-Aspartic acid and alkaline $\mathrm{Mn}$ (VII) has been studied over the range $2.0 \leq$ $10^{3}[$ Asp $] \leq 5.0 \mathrm{~mol} \mathrm{dm}^{-3} ; 0.01 \leq\left[\mathrm{OH}^{-}\right] \leq 0.05 \mathrm{~mol} \mathrm{dm}^{-3} ; 298$ $\leq T \leq 318 \mathrm{~K}$ and $I=0.05 \mathrm{~mol} \mathrm{dm}^{-3}\left(\mathrm{KNO}_{3}\right)$.

The reaction orders were determined using the slopes of $\log k_{\text {obs }}$ versus $\log \left[\mathrm{MnO}_{4}{ }^{-}\right]$plots by varying the concentration of the reductant and $\mathrm{OH}^{-}$while keeping other factors constant. With fixed concentrations of $D L$-Aspartic acid $1.0 \times 10^{-2} \mathrm{~mol} \mathrm{dm}^{-3}$, and alkali, $5.0 \times 10^{-2} \mathrm{~mol} \mathrm{dm}^{-3}$ at constant ionic strength, $0.05 \mathrm{~mol} \mathrm{dm}^{-3}$, the permanganate concentration varied from $1.0 \times 10^{-4} \mathrm{~mol} \mathrm{dm}^{-3}$ to $3.0 \times$ $10^{-4} \mathrm{~mol} \mathrm{dm}^{-3}$. The linearity of plots of $\log$ (absorbance) versus time, for different concentrations of permanganate, indicates that the order in $[\mathrm{Mn}(\mathrm{VII})]$ is unity (Figure 1 ). The $D L$-Aspartic acid concentration was varied in the range of $2.0 \times 10^{-3}$ to $5.0 \times 10^{-3} \mathrm{~mol} \mathrm{dm}^{-3}$ at constant alkali and permanganate concentrations and constant ionic strength of $0.05 \mathrm{~mol} \mathrm{dm}^{-3}$ at $298 \mathrm{~K}$. The $k_{\text {obs }}$ values increased with an increase in $D L$-Aspartic acid over the concentration range shown in Figure 3. At low concentration of $D L$-Aspartic acid, the reaction was of first order and at high concentration of $D L-$ Aspartic acid, the reaction was independent of DL-Aspartic acid.

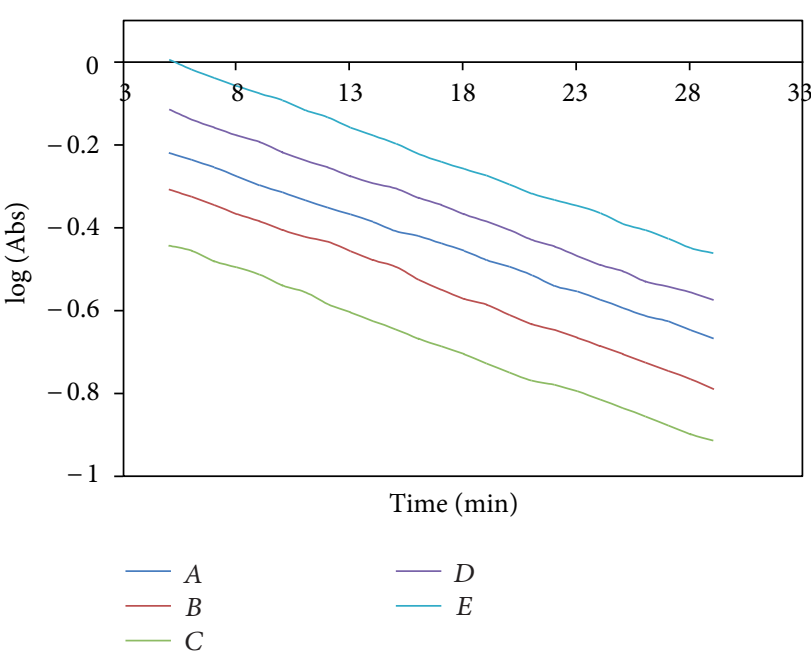

FIGURE 1: First-order plots of the oxidation of Aspartic acid by permanganate in aqueous alkaline medium. [Asp] $=2 \times 10^{-2} \mathrm{~mol} \mathrm{dm}^{-3}$, $\left[\mathrm{OH}^{-}\right]=0.02 \mathrm{~mol} \mathrm{dm}^{-3}, I=0.05 \mathrm{~mol} \mathrm{dm}{ }^{-3} \cdot 10^{4}\left[\mathrm{MnO}_{4}^{-}\right] \mathrm{mol} \mathrm{dm}^{-3}$, $\mathrm{A}=2.5, \mathrm{~B}=3.0, \mathrm{C}=2.5, \mathrm{D}=1.5$, and $\mathrm{E}=1.0$.

4.1. Effect of Alkali Concentration. The effect of alkali concentration on the reaction was studied at constant ionic strength of $0.05 \mathrm{~mol} \mathrm{dm}^{-3}$ at $25^{\circ} \mathrm{C}$. The $\left[\mathrm{OH}^{-}\right]$was varied in the range of 0.01 to $0.05 \mathrm{~mol} \mathrm{dm}^{-3}$. The rate constant increased with an increase in alkali concentration (Figure 4), indicating a fractional-order dependence of the rate on alkali concentration.

4.2. Effect of Ionic Strength. The effect of ionic strength was studied by varying the potassium nitrate concentration from 0.05 to $0.5 \mathrm{~mol} \mathrm{dm}^{-3}$ at constant concentration of permanganate, $D L$-Aspartic acid, and alkali. Increasing ionic strength had no effect on the rate constant.

4.3. Effect of Temperature. The kinetics was also studied at five different temperatures with varying concentrations of DL-Aspartic acid and alkali, keeping other conditions constant. The rate constants were found to increase with the increase in temperature. The rate of the slow step was obtained from the slopes and intercepts of $1 / k_{\text {obs }}$ versus $1 /\left[D L-\right.$ Aspartic acid] and $1 / k_{\text {obs }}$ versus $1 /\left[\mathrm{OH}^{-}\right]$plots at five different temperatures (298-318 K).

4.4. Test for Free Radical. To test for the involvement of free radicals, acrylonitrile was added to the reaction mixture, which was then kept for $24 \mathrm{~h}$ under nitrogen atmosphere. Addition of methanol, resulted in the precipitation of a polymer, suggesting the involvement of free radicals in the reaction. However, the blank experiments with reactants in presence of acrylonitrile did not respond to positive test for free radical formation. Initially added acrylonitrile decreased the rate of reaction [11].

4.5. Effect of Ionic Surfactants. It is well established that most of the micellar reactions involving an ionic or neutral 
reactants are believed to take place either inside the stern layer or at interface between the micellar surface and bulk solvent water $[12,13]$. The effect of the ionic and nonionic micelles on the reaction rates of bimolecular reactions is due to the association through electrostatic/hydrophobic and hydrogen bonding interactions between the reactants within a small volume of the self-assemblies [14]. During the study, the concentration of sodium dodecyl sulfate (SDS) varied keeping the concentrations of $\mathrm{DL}$-Aspartic acid, $\mathrm{MnO}_{4}{ }^{-}$, temperature and ionic strength constant (Table 3). With the increase in the concentration of SDS, the rate tends to attend a limiting value at high surfactant concentration indicating a micellar binding of the substrate. The equilibrium constant values for the formation of complex (C) with permanganate for $D L$-Aspartic acid and cysteine are comparable indicating equal probability of formation of the complex.

4.6. Stoichiometry and Product Analysis. The reaction between $D L$-Aspartic acid and $\mathrm{MnO}_{4}{ }^{-}$in alkaline medium has a stoichiometry of $1: 4$. The main reaction product is 3 -oxopropanoic acid. It was treated with 2,4-DNP and kept in refrigerator for 24 hours, a yellow solid was separated and recrystallized with ethanol. It was characterized by FT-IR. The FT-IR spectra of $D L$-Aspartic acid and its product complex are similar. The $\mathrm{C}=\mathrm{N}$ stretching band appears at $1619 \mathrm{~cm}^{-1}$ which is absent in DL-Aspartic acid. The other significant bands appear at $1411 \mathrm{~cm}^{-1}$ (for symmetric carboxylate stretching) $1520 \mathrm{~cm}^{-1}(\mathrm{~N}-\mathrm{H}$ bending). The other reaction products are identified as ammonia (Nessler's reagent test), $\mathrm{CO}_{2}$ (lime water test), and manganate $\left(\mathrm{MnO}_{4}{ }^{2-}\right)$.

\section{Discussion}

Under the experimental conditions at $\mathrm{pH}>12$, the reduction product of $\mathrm{Mn}(\mathrm{VII})$, that is, $\mathrm{Mn}(\mathrm{VI})$, is stable, and no further reduction is initially observed [15]. During this reaction, color changes from violet $\mathrm{Mn}(\mathrm{VII})$ to dark green $\mathrm{Mn}(\mathrm{VI})$ through blue $\mathrm{Mn}(\mathrm{IV})$. It is clear from Figure 2 that the absorbance of $\mathrm{MnO}_{4}{ }^{-}$decreases at $525 \mathrm{~nm}$, while increases at 630 and $430 \mathrm{~nm}$ are due to $\mathrm{Mn}(\mathrm{VI})$. As the reaction proceeds, a yellow turbidity slowly develops, and after keeping for a long time the solution decolorizes and forms a brown precipitate. This suggests that the initial products might have undergone further oxidation resulting in a lower oxidation state of manganese. It appears that the alkali combines with permanganate to give $\left[\mathrm{MnO}_{4} \cdot \mathrm{OH}\right]^{2-}[16,17]$. In the second step, $\left[\mathrm{MnO}_{4} \cdot \mathrm{OH}\right]^{2-}$ combines with $D L$-Aspartic to form an intermediate complex. The variable order with respect to $D L^{-}$ Aspartic is most probably due to the complex formation between oxidant and DL-Aspartic prior to the slow step. A plot of $1 / k_{\text {obs }}$ versus $1 /[$ Asp] (Figure 3) shows an intercept in agreement with complex formation. Further evidence for complex formation was obtained from the UV-vis spectra of reaction mixture. Two isosbestic point were observed for this reaction (Figure 2), indicating the presence of an equilibrium before the slow step of the mechanism $[18,19]$.

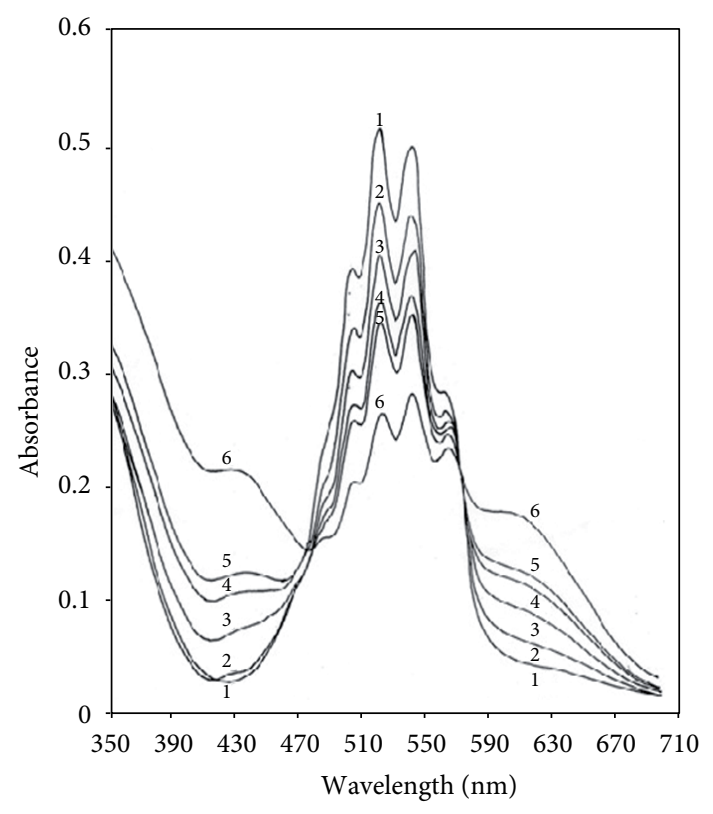

FIGURE 2: Spectral changes during the oxidation of $D L$-Aspartic acid by permanganate in alkaline medium at $303 \mathrm{~K}: 10^{4}\left[\mathrm{MnO}_{4}{ }^{-}\right]$ $=2.0 \mathrm{~mol} \mathrm{dm}^{-3}, 10^{3}[\mathrm{Asp}]=2.0 \mathrm{~mol} \mathrm{dm}{ }^{-3}$, and $10^{2}\left[\mathrm{OH}^{-}\right]=$ $1.0 \mathrm{~mol} \mathrm{dm}^{-3}$ and $I=0.05 \mathrm{~mol} \mathrm{dm}{ }^{-3}$. 1: mixture immediately after mixing; 2, 3, 4, 5, and 6 after $5 \mathrm{~min}, 10 \mathrm{~min}, 15 \mathrm{~min}, 20 \mathrm{~min}$, and 25 min, respectively.

In our proposed mechanism, in the complex one electron is transferred from aspartic acid to $\mathrm{Mn}(\mathrm{VII})$. The cleavage of this complex (C) is assigned as the slowest step, leading to the formation of an $D L$-Aspartic radical intermediate and $\mathrm{Mn}(\mathrm{VI})$. The radical intermediate reacts with another $\mathrm{Mn}(\mathrm{VII})$ species, $\left[\mathrm{MnO}_{4} \cdot \mathrm{OH}\right]^{2-}$, to give the final products: $\mathrm{Mn}(\mathrm{VI}), 3$-oxopropanic acid and $\mathrm{NH}_{3}$ (Scheme 1). The effect of the ionic strength and dielectric constant on the rate is consistent with the involvement of a neutral molecule in the reaction. The suggested structure of complex $(C)$ is given in Scheme 1.

From Scheme 1, the rate law can be derived as follows:

$$
\text { Rate }=\frac{-\mathrm{d}\left[\mathrm{MnO}_{4}^{-}\right]}{\mathrm{d} t}=k K_{1} K_{2}\left[\mathrm{MnO}_{4}^{-}\right]_{f}[\mathrm{Asp}]_{f}\left[\mathrm{OH}^{-}\right]_{f} \text {. }
$$

The total $\left[\mathrm{MnO}_{4}{ }^{-}\right]$can be written as

$$
\begin{aligned}
{\left[\mathrm{MnO}_{4}^{-}\right]_{t}=} & {\left[\mathrm{MnO}_{4}^{-}\right]_{f} } \\
& \times\left(1+K_{1}\left[\mathrm{OH}^{-}\right]+K_{1} K_{2}[\mathrm{Asp}]\left[\mathrm{OH}^{-}\right]\right), \\
{\left[\mathrm{MnO}_{4}^{-}\right]_{f}=} & \frac{\left[\mathrm{MnO}_{4}^{-}\right]_{t}}{1+K_{1}\left[\mathrm{OH}^{-}\right]+K_{1} K_{2}[\mathrm{Asp}]\left[\mathrm{OH}^{-}\right]},
\end{aligned}
$$


TABLE 1: Effect of [ $D L$-Aspartic acid], $\left[\mathrm{MnO}_{4}^{-}\right]$, and $\left[\mathrm{OH}^{-}\right]$on the oxidation of $D L$-Aspartic acid by permanganate in aqueous alkaline medium at $298 \mathrm{~K} .\left[\mathrm{MnO}_{4}^{-}\right]=2.0 \times 10^{-4} \mathrm{~mol} \mathrm{dm}{ }^{-3}$ and $I=0.05 \mathrm{~mol} \mathrm{dm}^{-3}$.

\begin{tabular}{|c|c|c|c|}
\hline$\left[\mathrm{OH}^{-}\right]\left(\mathrm{mol} \mathrm{dm}^{-3}\right)$ & $10^{2}[D L$-Aspartic acid $]\left(\mathrm{mol} \mathrm{dm}^{-3}\right)$ & $10^{3} k_{\mathrm{obs}}\left(\mathrm{s}^{-1}\right)$ & $R^{2}$ \\
\hline 0.01 & 0.2 & 0.13 & 0.99 \\
\hline 0.01 & 0.3 & 0.18 & 0.98 \\
\hline 0.01 & 0.4 & 0.24 & 0.98 \\
\hline 0.01 & 0.5 & 0.29 & 0.97 \\
\hline 0.02 & 0.2 & 0.25 & 0.99 \\
\hline 0.02 & 0.3 & 0.31 & 0.98 \\
\hline 0.02 & 0.4 & 0.38 & 0.99 \\
\hline 0.02 & 0.5 & 0.44 & 0.97 \\
\hline 0.03 & 0.2 & 0.35 & 0.98 \\
\hline 0.03 & 0.3 & 0.42 & 0.98 \\
\hline 0.03 & 0.4 & 0.47 & 0.99 \\
\hline 0.03 & 0.5 & 0.54 & 0.99 \\
\hline 0.04 & 0.2 & 0.44 & 0.97 \\
\hline 0.04 & 0.3 & 0.50 & 0.99 \\
\hline 0.04 & 0.4 & 0.56 & 0.98 \\
\hline 0.04 & 0.5 & 0.63 & 0.98 \\
\hline 0.05 & 0.2 & 0.53 & 0.99 \\
\hline 0.05 & 0.3 & 0.60 & 0.99 \\
\hline 0.05 & 0.4 & 0.67 & 0.97 \\
\hline 0.05 & 0.5 & 0.76 & 0.98 \\
\hline
\end{tabular}

TABLE 2: Activation and thermodynamic parameters for the oxidation of $D L$-Aspartic acid by alkaline $\mathrm{KMnO}_{4}$ with respect to the slow step of the reaction (Scheme 1).

\begin{tabular}{|c|c|c|}
\hline \multicolumn{3}{|c|}{ Effect of temperature with respect to the slow step of Scheme $1\left[\mathrm{OH}^{-}\right]=0.01 \mathrm{~mol} \mathrm{dm}^{-3},[$ Asp $]=0.004 \mathrm{~mol} \mathrm{dm}^{-3}$} \\
\hline Temperature $(\mathrm{K})$ & $10^{3} k\left(\mathrm{~s}^{-1}\right)$ & $R^{2}$ \\
\hline 298 & 0.24 & 0.99 \\
\hline 303 & 0.29 & 0.99 \\
\hline 308 & 0.34 & 0.99 \\
\hline 313 & 0.39 & 0.98 \\
\hline 318 & 0.44 & 0.99 \\
\hline \multicolumn{3}{|l|}{ Activation parameters } \\
\hline$E_{a}\left(\mathrm{~kJ} \mathrm{~mol}^{-1}\right)$ & \multicolumn{2}{|l|}{23.8} \\
\hline$\Delta H^{\#}\left(\mathrm{~kJ} \mathrm{~mol}^{-1}\right)$ & \multicolumn{2}{|l|}{$5.6 \pm 0.3$} \\
\hline$\Delta S^{\#}\left(\mathrm{JK}^{-1} \mathrm{~mol}^{-1}\right)$ & \multicolumn{2}{|l|}{$-227.6 \pm 1.1$} \\
\hline$\Delta G^{\#}\left(\mathrm{~kJ} \mathrm{~mol}^{-1}\right)(298 \mathrm{~K})$ & $\Delta G^{\#}\left(\mathrm{~kJ} \mathrm{~mol}{ }^{-1}\right)(298 \mathrm{~K})$ & \\
\hline$T(\mathrm{~K})$ & $\begin{array}{l}\text { re on equilibrium con } \\
10^{-2} K_{1}\left(\mathrm{dm}^{3} \mathrm{~mol}^{-1}\right)\end{array}$ & $10^{-3} K_{2}\left(\mathrm{dm}^{3} \mathrm{~mol}^{-1}\right)$ \\
\hline 298 & 1.3 & 1071.0 \\
\hline 303 & 0.7 & 1139.5 \\
\hline 308 & 3.2 & 978.9 \\
\hline 313 & 11.1 & 955.7 \\
\hline 318 & 20.2 & 891.1 \\
\hline
\end{tabular}

where " $t$ " and " $f$ " stand for "total" and "free", respectively. Similarly, total $\left[\mathrm{OH}^{-}\right]$can be calculated as

$$
\begin{aligned}
& {\left[\mathrm{OH}^{-}\right]_{t}=\left[\mathrm{OH}^{-}\right]_{f}+\left[\mathrm{MnO}_{4} \cdot \mathrm{OH}\right]^{2-}+[\text { Complex C }]} \\
& {\left[\mathrm{OH}^{-}\right]_{f}=\frac{\left[\mathrm{OH}^{-}\right]_{t}}{1+K_{1}\left[\mathrm{MnO}_{4}^{-}\right]+K_{1} K_{2}[\text { Asp }]\left[\mathrm{MnO}_{4}^{-}\right]} .}
\end{aligned}
$$

In view of the low concentration of $\mathrm{MnO}_{4}{ }^{-}$and $\mathrm{DL}$-Aspartic acid used in the experiment, in (3), the terms $K_{1}\left[\mathrm{MnO}_{4}{ }^{-}\right]$and $K_{1} K_{2}\left[\right.$ Asp] $\left[\mathrm{MnO}_{4}^{-}\right]$can be neglected.

Thus,

$$
\left[\mathrm{OH}^{-}\right]_{f}=\left[\mathrm{OH}^{-}\right]_{t} \text {. }
$$


TABLE 3: Effect of SDS on the oxidation of $D L$-Aspartic acid by permanganate in aqueous alkaline medium at $298 \mathrm{~K},\left[\mathrm{MnO}_{4}{ }^{-}\right]=2.0$ $\times 10^{-4} \mathrm{~mol} \mathrm{dm}^{-3},[D L$-Aspartic acid $]=2.0 \times 10^{-3} \mathrm{~mol} \mathrm{dm}^{-3},\left[\mathrm{OH}^{-}\right]$ $=1.0 \times 10^{-2} \mathrm{~mol} \mathrm{dm}^{-3}$, and $I=0.05 \mathrm{~mol} \mathrm{dm}^{-3}$.

\begin{tabular}{lc}
\hline$[\mathrm{SDS}]\left(\mathrm{mol} \mathrm{dm}^{-3}\right)$ & $10^{4} k_{\mathrm{obs}}\left(\mathrm{s}^{-1}\right)$ \\
\hline 0.000 & 10.2 \\
0.005 & 13.8 \\
0.010 & 16.4 \\
0.015 & 17.6 \\
0.020 & 18.5 \\
0.025 & 19.4 \\
0.030 & 20.4 \\
0.035 & 21.1 \\
0.040 & 21.5 \\
\hline
\end{tabular}

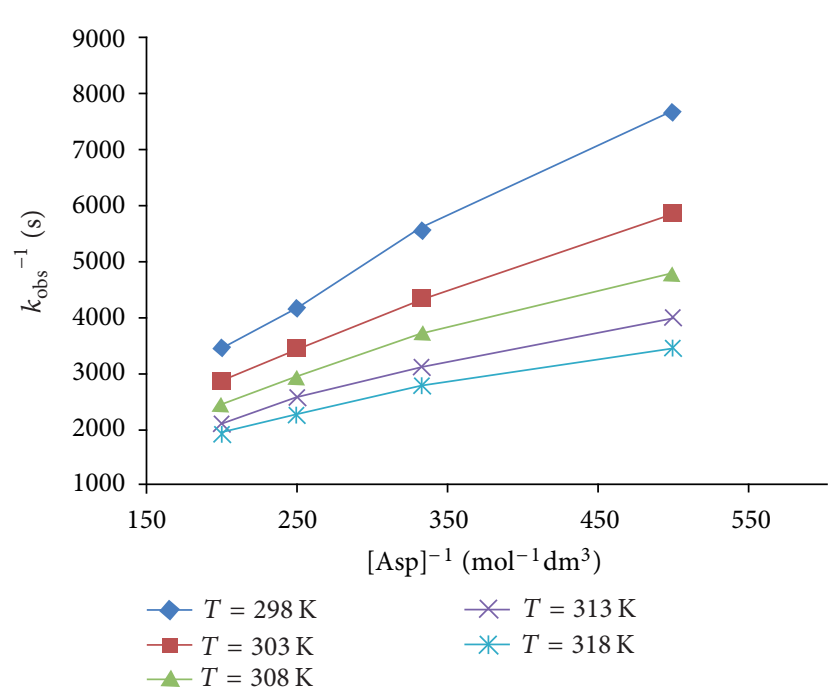

Figure 3: Plots of $1 / k_{\text {obs }}$ versus $1 /$ [Asp] at five different temperatures. $10^{2}\left[\mathrm{OH}^{-}\right]_{T}=1.0 \mathrm{~mol} \mathrm{dm}{ }^{-3}, 10^{4}\left[\mathrm{MnO}_{4}{ }^{-}\right]_{T}=2.0 \mathrm{~mol} \mathrm{dm}{ }^{-3}$, and $I=0.05 \mathrm{~mol} \mathrm{dm}^{-3} \cdot 10^{3}[\mathrm{Asp}]_{T}$ varied from 2.0 to $5.0 \mathrm{~mol} \mathrm{dm}^{-3}$.

Similarly,

$$
[\mathrm{Asp}]_{f}=[\mathrm{Asp}]_{t} .
$$

Substituting (3), (5), and (6) in (2), we get

$$
\begin{aligned}
& {\left[\mathrm{MnO}_{4}^{-}\right]_{f}=\frac{1+K_{1}\left[\mathrm{OH}^{-}\right]+K_{1} K_{2}[\mathrm{Asp}]\left[\mathrm{OH}^{-}\right]}{1+K_{1}\left[\mathrm{OH}^{-}\right]+K_{1} K_{2}[\mathrm{Asp}]\left[\mathrm{OH}^{-}\right]},} \\
& \frac{\text { Rate }}{\left[\mathrm{MnO}_{4}^{-}\right]}=k_{\text {obs }}=\frac{k K_{1} K_{2}[\mathrm{Asp}]\left[\mathrm{OH}^{-}\right]}{1+K_{1}\left[\mathrm{OH}^{-}\right]+K_{1} K_{2}[\mathrm{Asp}]\left[\mathrm{OH}^{-}\right]} .
\end{aligned}
$$

Equation (8) is consistent with the observed orders with respect to different species, which can be verified by rearranging to (9)

$$
\frac{1}{k_{\mathrm{obs}}}=\frac{1}{k K_{1} K_{2}[\mathrm{Asp}]\left[\mathrm{OH}^{-}\right]}+\frac{1}{k K_{2}[\mathrm{Asp}]}+\frac{1}{k} .
$$

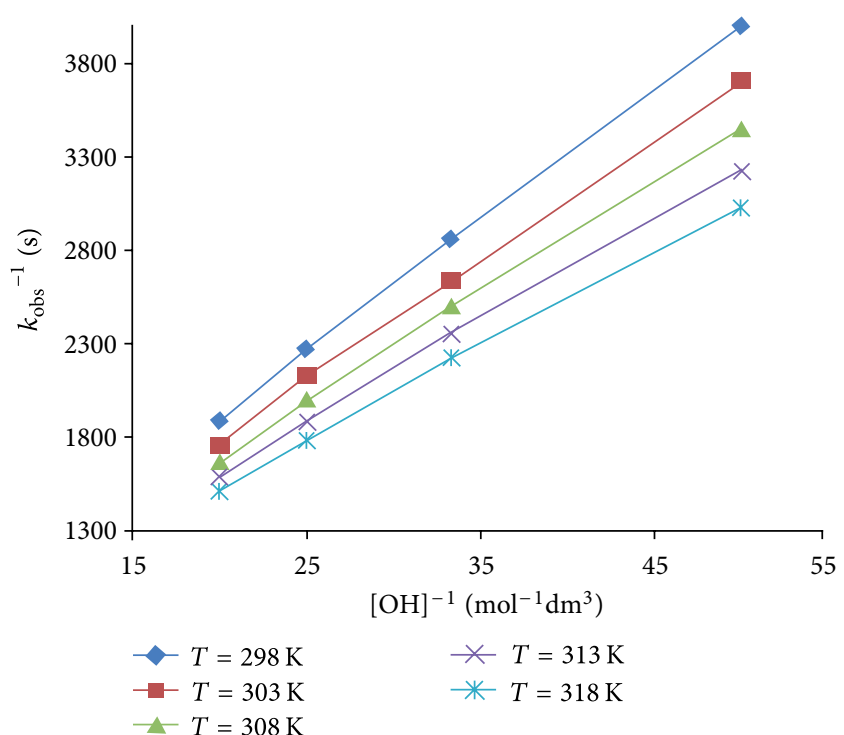

FIGURE 4: Plots of $1 / k_{\text {obs }}$ versus $1 /\left[\mathrm{OH}^{-}\right]$at five different temperatures. $10^{3}[\mathrm{Asp}]_{T}=2.0 \mathrm{~mol} \mathrm{dm}{ }^{-3}, 10^{4}\left[\mathrm{MnO}_{4}^{-}\right]_{T}=2.0 \mathrm{~mol} \mathrm{dm}^{-3}$, and $I=0.05 \mathrm{~mol} \mathrm{dm}^{-3} \cdot 10^{2}\left[\mathrm{OH}^{-}\right]_{T}$ varied from 2.0 to $5.0 \mathrm{~mol} \mathrm{dm}^{-3}$.

According to (9), other conditions being constant, plots of $1 / k_{\text {obs }}$ versus $1 /[$ Asp $]$ and $1 / k_{\text {obs }}$ versus $1 /\left[\mathrm{OH}^{-}\right]$should be linear (Figures 3 and 4). The slopes and intercepts of such plots lead to values of $K_{1}, K_{2}$, and $k$ (Table 2). With these values, the rate constants were calculated under different experimental conditions. The thermodynamic quantities for the first and second equilibrium steps of Scheme 1 can be evaluated. The $[D L$-Aspartic acid $]$ and $\left[\mathrm{OH}^{-}\right]$(Table 1$)$ were varied at five different temperatures. van't Hoff's plots of $\log K_{1}$ versus $1 / T$ and $\log K_{2}$ versus $1 / T$ gave the values of enthalpy of reaction $\Delta H^{\circ}$, entropy of reaction $\Delta S^{\circ}$, and free energy of reaction $\Delta G^{\circ}$, calculated for the first and second equilibrium steps (Table 2). A comparison of the later values (from $K_{2}$ ) with those obtained for the slow step of the reaction shows that they mainly refer to the rate-limiting step, supporting the fact that the reaction before the ratedetermining step is fairly fast and involves low activation energy $[20,21]$. The moderate values of $\Delta S^{\circ}$ were both favorable for the electron transfer processes. The values of $\Delta S^{\circ}$, that is within the expected range for radical reactions, have been ascribed to the nature of electron pairing and unpairing processes and the loss of degrees of freedom formerly available to the reaction upon the formation of a rigid transition state [22]. The negative values of $\Delta S^{\circ}$ indicate that the complex $(\mathrm{C})$ is more ordered than the reactants $[23,24]$. The enthalpy of activation and a relatively low value of entropy and a higher rate constant of the slow step indicate that the oxidation most probably occurs via inner-sphere mechanism $[25,26]$.

\section{Conclusion}

It is noteworthy that the oxidant species $\mathrm{MnO}_{4}{ }^{-}$required the $\mathrm{pH} 12$, below which the system gets disturbed and the 


$$
\mathrm{MnO}_{4}^{-}+\mathrm{OH}^{-} \stackrel{K_{1}}{=}\left[\mathrm{MnO}_{4} \cdot \mathrm{OH}\right]^{2-}
$$

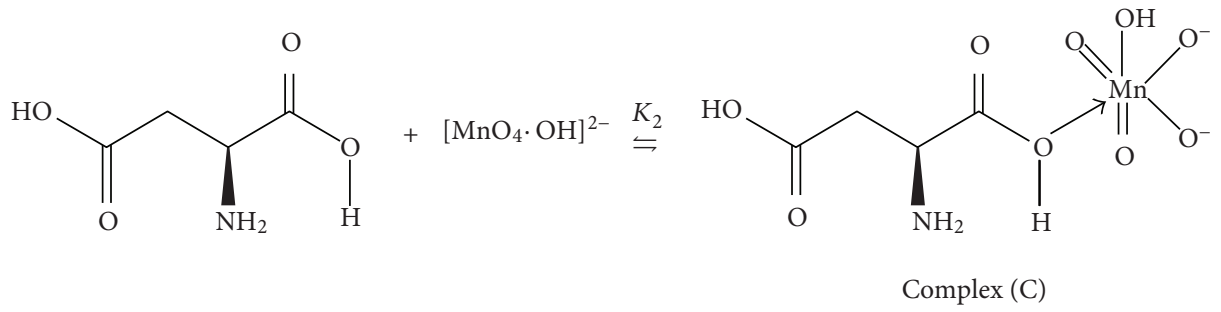

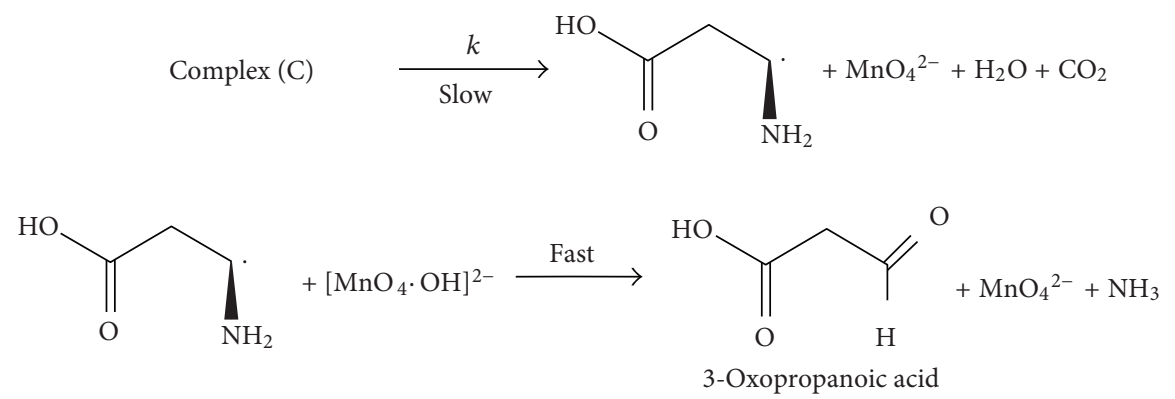

Scheme 1: Proposed mechanism for the oxidation of $D L$-Aspartic acid by alkaline $\mathrm{MnO}_{4}{ }^{-}$.

reaction proceeds further to give a more reduced state of $\mathrm{Mn}$, that is, Mn(IV) which slowly develops yellow turbidity. In this reaction, the role of $\mathrm{pH}$ is crucial. The rate constant of the slowest step and other equilibrium constants involved in the mechanism were evaluated and activation parameters were calculated. The proposed mechanism is consistent with product, mechanistic, and kinetic studies.

\section{References}

[1] H. A. Krebs, The Nobel Lecture, 1953.

[2] M. Akram, M. Altaf, and Kabir-ud-Din, "Oxidation of aspartic acid by water soluble colloidal $\mathrm{MnO}_{2}$ in absence and presence of ionic and nonionic surfactants," Indian Journal of Chemistry A, vol. 46, no. 9, pp. 1427-1431, 2007.

[3] A. Arrizabalaga, F. J. Andrés-Ordax, M. Y. FernándezAránguiz, and R. Peche, "Kinetics and mechanism of the oxidation of $\mathrm{L}-\alpha$-amino- $n$-butyric acid by permanganate in acid medium," International Journal of Chemical Kinetics, vol. 28, no. 11, pp. 799-805, 1996.

[4] A. Arrizabalaga, F. I. Andrés-Ordax, M. Y. FernándezAránguiz, and R. Peche, "Kinetic studies on the permanganic oxidation of amino acids. Effect of the length of amino acid carbon chain," International Journal of Chemical Kinetics, vol. 29, no. 3, pp. 181-185, 1997.

[5] G. Ionita, V. E. Sahini, G. Semenescu, and P. Ionita, "Kinetics of oxidation of amino acids by some free stable hydrazyl radicals," Acta Chimica Slovenica, vol. 47, no. 1, pp. 111-119, 2000.

[6] J. M. Pullar, M. C. M. Vissers, and C. C. Winterbourn, "Glutathione oxidation by hypochlorous acid in endothelial cells produces glutathione sulfonamide as a major product but not glutathione disulfide," The Journal of Biological Chemistry, vol. 276, no. 25, pp. 22120-22125, 2001.
[7] Sonbol and H. Ridha, Journal of SaudiChemical Society, vol. 7, p. $187,2003$.

[8] N. Nalwaya, A. Jain, and B. L. Hiran, "Oxidation of some $\alpha$ amino acids by pyridinium bromochromate in an aquo-acetic acid medium - a kinetic and mechanistic study," Kinetics and Catalysis, vol. 45, no. 3, pp. 345-350, 2004.

[9] R. B. Chougale, R. G. Panari, and S. T. Nandibewoor, "Kinetics and mechanism of alkaline permanganate oxidation of $\mathrm{L}(+)$ aspartic acid," Oxidation Communications, vol. 22, no. 2, pp. 298-307, 1999.

[10] A. I. Vogel, Text Book of Quantitative Chemical Analysis, Longman, Essex, UK, 5th edition, 1989.

[11] S. Bhattacharya and P. Banerjee, "Kinetic studies on the electron transfer between azide and nickel(IV) oxime imine complexes in aqueous solution," Bulletin of the Chemical Society of Japan, vol. 69, no. 12, pp. 3475-3482, 1996.

[12] E. H. Cordes, "Kinetics of organic reaction in micelles," Pure and Applied Chemistry, vol. 50, no. 7, pp. 617-625, 1978.

[13] E. H. Cordes and R. B. Dunlap, "Kinetics of organic reactions in micellar systems," Accounts of Chemical Research, vol. 2, no. 11, pp. 329-337, 1969.

[14] J. H. Fendler and E. J. Fendler, Catalysis in Micellar and Macromolecular Systems, Academic Press, New York, NY, USA, 1975.

[15] P. L. Timmanagoudar, G. A. Hiremath, and S. T. Nandibewoor, "Permanganate oxidation of chromium(III) in aqueous alkaline medium: a kinetic study by the stopped-flow technique," Transition Metal Chemistry, vol. 22, no. 2, pp. 193-196, 1997.

[16] R. G. Panari, R. B. Chougale, and S. T. Nandibewoor, "Oxidation of mandelic acid by alkaline potassium permanganate. A kinetic study," Journal of Physical Organic Chemistry, vol. 11, no. 7, pp. 448-454, 1998. 
[17] K. A. Thabaj, S. D. Kulkarni, S. A. Chimatadar, and S. T. Nandibewoor, "Oxidative transformation of ciprofloxacin by alkaline permanganate-a kinetic and mechanistic study," Polyhedron, vol. 26, no. 17, pp. 4877-4885, 2007.

[18] R. Chang, Physical Chemistry with Applications to Biological Systems, MacMillan, New York, NY, USA, 1981.

[19] D. N. Sathyanarayana, Electronic Absorption Spectroscopy and Related Techniques, Universities Press, Andhra Pradesh, India, 2001.

[20] K. S. Rangappa, M. P. Raghavendra, D. S. Mahadevappa, and D. Channegowda, "Sodium N-chlorobenzenesulfonamide as a selective oxidant for hexosamines in alkaline medium: a kinetic and mechanistic study," Journal of Organic Chemistry, vol. 63, no. 3, pp. 531-536, 1998.

[21] D. C. Bilehal, R. M. Kulkarni, and S. T. Nandibewoor, "Kinetics and mechanistic study of the ruthenium(III) catalyzed oxidative deamination and decarboxylation of $L$-valine by alkaline permanganate," Canadian Journal of Chemistry, vol. 79, no. 12, pp. 1926-1933, 2001.

[22] C. Walling, Free Radicals in Solution, Academic Press, New York, NY, USA, 1957.

[23] K. S. Rangappa, N. Anitha, and N. M. M. Gowda, "Mechanistic investigations of the oxidation of substituted phenethyl alcohols by manganese(III) sulfate catalyzed by ruthenium(III) in acid solution," Synthesis and Reactivity in Inorganic and MetalOrganic Chemistry, vol. 31, no. 8, pp. 1499-1518, 2001.

[24] Z. D. Bugarić, S. T. Nandibewoor, M. S. A. Hamza, F. Heinemann, and R. van Eldik, "Kinetics and mechanism of the reactions of $\mathrm{Pd}(\mathrm{II})$ complexes with azoles and diazines. Crystal structure of $\left[\mathrm{Pd}(\mathrm{bpma})\left(\mathrm{H}_{2} \mathrm{O}\right)\right]\left(\mathrm{ClO}_{4}\right)_{2} \cdot 2 \mathrm{H}_{2} \mathrm{O}$," Dalton Transactions, no. 24, pp. 2984-2990, 2006.

[25] K. W. Hicks, "Kinetics of the permanganate ion-potassium octacyanotungstate(IV) reaction," Journal of Inorganic and Nuclear Chemistry, vol. 38, no. 7, pp. 1381-1383, 1976.

[26] S. A. Farokhi and S. T. Nandibewoor, "Kinetic, mechanistic and spectral studies for the oxidation of sulfanilic acid by alkaline hexacyanoferrate(III)," Tetrahedron, vol. 59, no. 38, pp. 7595-7602, 2003. 

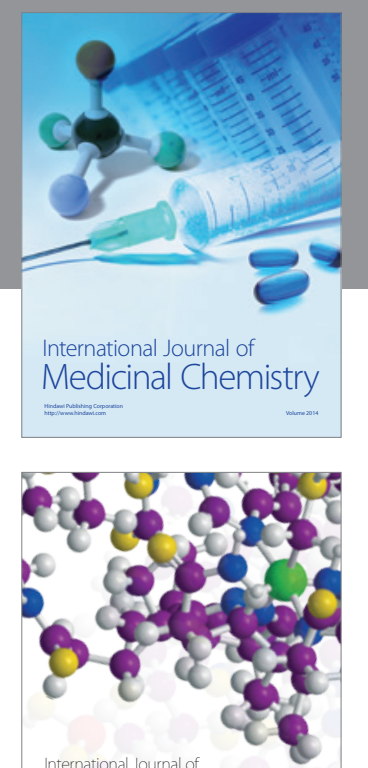

\section{Carbohydrate} Chemistry

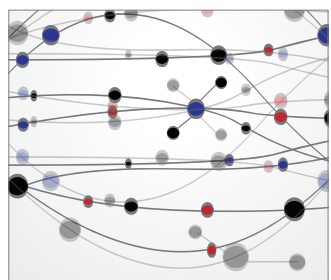

The Scientific World Journal
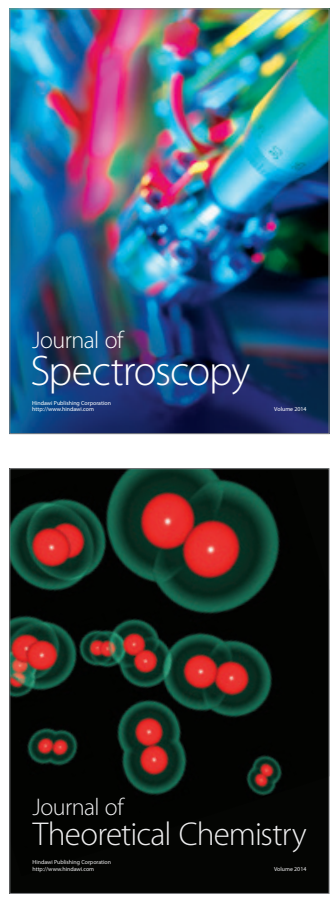
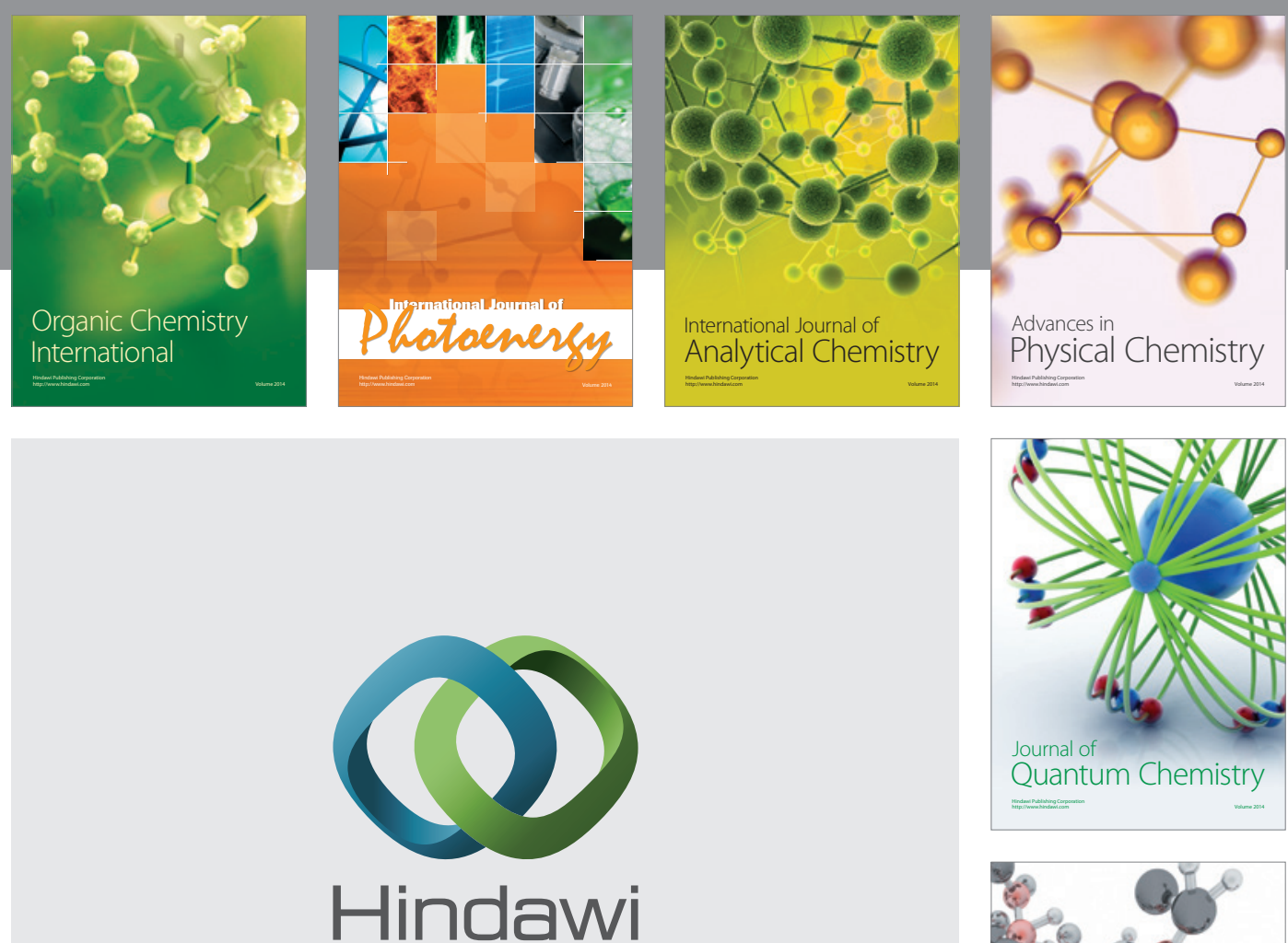

Submit your manuscripts at

http://www.hindawi.com

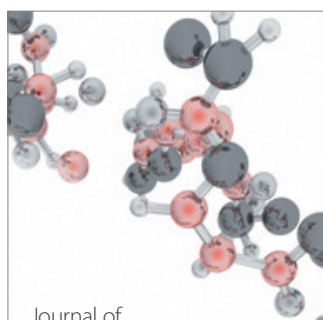

Analytical Methods

in Chemistry

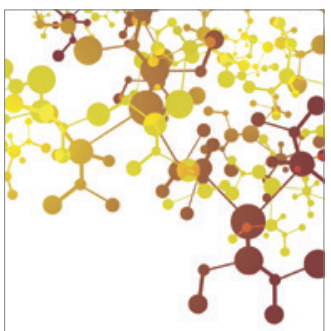

Journal of

Applied Chemistry

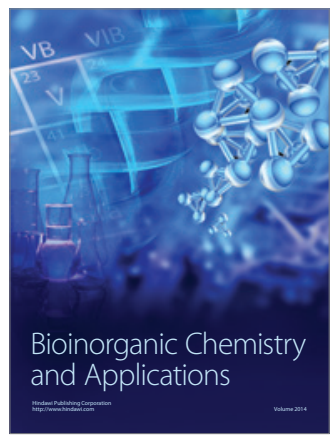

Inorganic Chemistry
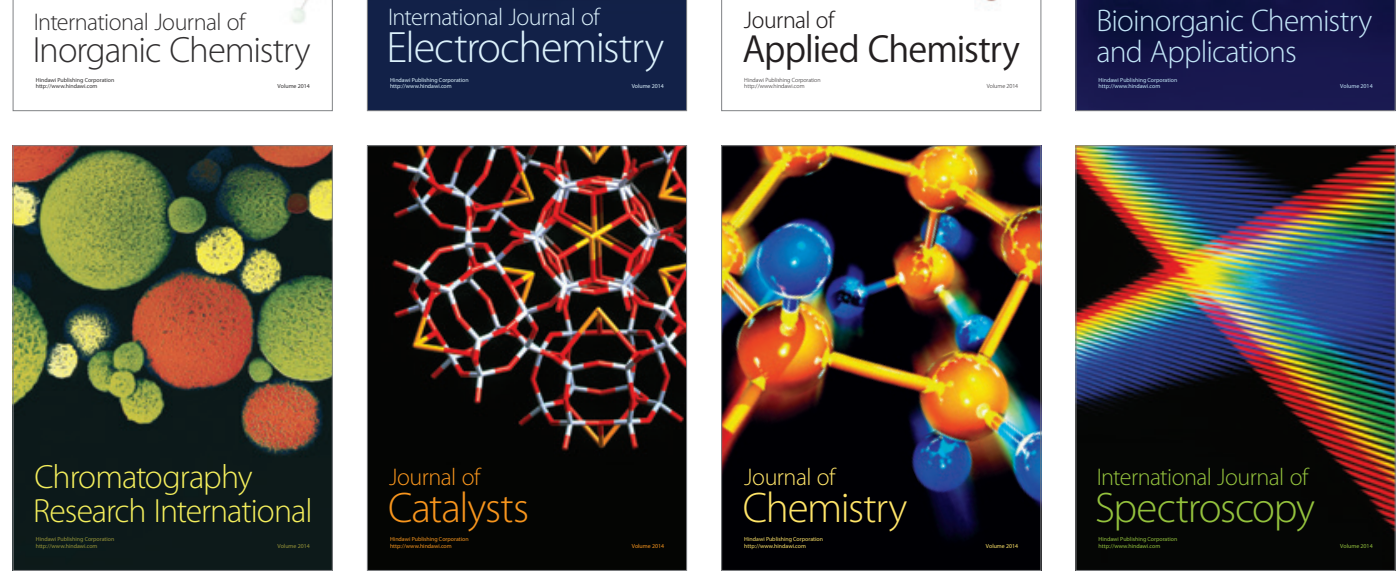